\title{
Judging Inappropriateness in Actions Expressing Emotion: A Feminist Perspective
}

\author{
Frances Bottenberg
}

In the 1949 film Adam's Rib, Amanda Bonner (Katharine Hepburn) begins to cry during a quarrel with her husband Adam (Spencer Tracy). Mr. Bonner, in a tone that bespeaks exasperation, says: "Here we go again, the old juice. Guaranteed heartbreaker. A few female tears. Stronger than any acid. But this time it won't work."

Mrs. Bonner's crying is ineffectual because, in her husband's eyes at least, it is an emotional behaviour that is excessive to the matter at hand, i.e. the argument. But why does he mark this behaviour as excessive? Is the fact that her husband perceives the tears as ineffectual sufficient to discredit them? If we know (as we do by that time in the film) that Mrs. Bonner has used her actions expressing emotion (such as crying) in the past to deflect attention from the matter at hand (using her tears as a red herring)—we are more likely to side with her husband's assessment. However, even if we know of Mrs. Bonner's past behaviours, a troubling question persists: what if her tears are genuinely produced this time, and Mr. Bonner's words amount to an unfair attack on his partner? If this is the case, then his words ought be turned against him, since they speak to a moral insensitivity on his part rather than to an excessiveness on hers. In fact, if this is the case, then his words reveal not just an insensitivity towards her, a particular woman who is crying, but to all women: the generalizing sentiment of his "A few female tears" and "Here we go again, the old juice" presents a picture of women's crying behaviours as general annoyances and hindrances to rational discourse. Enter masculinist bias.

These interpretations of the Bonner quarrel scene hint at the epistemic and moral complexities involved in applying the concepts of excessiveness and irrationality particularly to women's actions expressing emotion. Broadly, the concepts of excessiveness and irrationality mark violations of normative appropriateness. The trouble with public displays of emotion, however, lies in determining what factors are involved in such assessment. Further, there is the matter of how the degree of an infraction is determined. Naively or in an informed way, we invariably rely on 
heuristics to decide whether to classify one offense as mild and easy to look past and another as so severe as to be deemed pathological.

This paper analyzes the common charge of inappropriateness in the case of women's actions expressing emotion. I structure this analysis into three sections. First, core normative distinctions that generally define appropriate emotional expression will be presented. Then, looking at the case of women diagnosed with Borderline Personality Disorder, I will explore the double-bind which women are in when it comes to expressing emotion publicly. Nancy Potter articulates this double-bind as follows: "If [women] are vehement in their expressions of anger, they may be viewed as pathologically angry. If they are already viewed as 'too angry', then their denying that they are angry is proof of regression" (61). Supported by arguments for the conscious rejection of gendered norms in the case of actions expressing emotions, the third and final section of the paper explores epistemically and ethically viable alternatives for deciding the rational appropriateness of actions expressing emotion.

\section{I}

Norms defining and constraining behaviour being plentiful, I wish to focus on those which come into play when actions expressing emotion are interpersonally assessed. First, I propose two overarching rational modes into which norms used in the identification of (in)appropriate emotion-sourced action fall. In outlining these modes, I build on Patricia Greenspan's work on the rationality of emotion, and in particular her distinction of evidential and instrumental rationality (her terms). The norms of evidential rationality are epistemic in nature; they have to do with someone's getting the facts right and drawing strong inferences from them. For example, the person who acts delighted upon learning she has been awarded a coveted hire is an example of emotion-expressive action that coheres with epistemic norms-landing a job one hoped for is a reason for contentment and celebration. To express delight on such an occasion is thus epistemically appropriate and evidentially rational. Alternatively, the partner who acts out his jealousy despite having no evidence in support of his belief of being cheated on, and plenty of evidence to the contrary, is an example of emotion-expressive action that violates epistemic norms and as a result is epistemically inappropriate and thus evidentially irrational.

I would add to Greenspan's discussion a second key group of norms that govern evidential rationality: those which adjudicate the appropriateness of value attributions and the drawing of inferences based on these attributions. Evaluative norms must be at least partially distinct of epistemic norms, since it is easy to imagine a case where a person has the facts right but still acts in a way that is judged evidentially inappropriate. 
For example, consider what Sandel terms "hyper-parenting," the modernday fad of the aggressive promotion of one's own children at lengths that seem inappropriate to everyone except the parents. There is the perennial local media coverage, for instance, of a parent becoming enraged and even physically assaulting a referee at his child's sports game. Investigation of such a case and others like it will reveal that the agent has under- or overvalued the salience of a given fact within his or her reasoning - in the case of the hyperparent, anything that criticizes the child is deemed a violation. Because our emotional life is intrinsically bound to our valuings, if someone has an out-of-touch set of value priorities, this will come to light through his or her emotion-sourced qua valuing-sourced behaviour.

So on the one hand, we have:

\section{Norms of evidential rationality}

\section{i. Epistemic norms}

\section{ii. Evaluative norms}

Actions expressing emotions ought first be appraised in terms of their apparent (in)coherence with these norms of evidential rationality. On the other hand, there is the vast territory of social mores, interpersonal communication, and first-person coping. These represent facets of instrumental rationality, Greenspan's second rational mode, which concerns the role of behaviour in determining an interpersonal or intrapersonal effect. An intended intrapersonal effect falls under what I term self-relevant coping, while interpersonal effects are tokens of social coping. It is certainly possible to imagine one behaviour being a case of both self-relevant coping and social coping. For that reason, and for the sake of visual simplicity, I list self-relevant coping alongside six other normative subdivisions within social coping. Each bears brief introduction and illustration:

\section{Norms of instrumental rationality}

\section{Group 1.}

i. Agency norms have to do with the apparent voluntariness or involuntariness of action-a "first test" which must be passed for further judgments of appropriateness to be levelled against the agent. Persons with certain cognitive disabilities, sleepwalkers, and intoxicated individuals fall outside this parameter, because they are held less strategically accountable for their actions, due to the relative lack of control over them.

ii. Practice-specific norms cover the boundless number of practices, professions, rituals, group habits, games, ceremonies, memes, etc. which abound in human society. A funeral calls for very different emotional behaviour than a wedding does, a poker 
player must radically change her expressive bearing to play at charades, and an "academic" stance during a meeting with friends may leave an impression of aloofness.

iii. Self-relevant coping norms include behaviours such as avoiding assault, venting stress, and overcoming trauma. The appropriateness of emotional behaviour associated with these actions is difficult to assess by an outsider, since they are elicited by the one coping him- or herself, in reaction to a prior stressful, traumatic or unpleasant event, rather than the occurrent interpersonal context.

\section{Group 2.}

iv. Developmental norms define how age groups are expected to behave. A precocious child is often perceived to be strangely adult, and greedy, power-hungry adults are unflatteringly likened to children. The cases of cognitive disability and some forms of physical impairment problematize these norms, yet they remain pervasive and deep-seated.

v. Class norms come into play with socio-economic status. The nouveau riche, for instance, were given their name precisely to mark their behaviours and mannerisms as different from "old money." Or take the Dickensonian picture of the moral characters of rich and poor, in which the poor are expected to be obsequious, pious, and humble, in contrast to the ultra-rich who are expected to be bossy, demanding, and callous.

vi. Cultural norms catch those standards that we apply to each other as members of a particular country and region of the world. Many a joke has been made at the expense of the stiff, laconic Swede and the effusive, buoyant Sicilian.

vii. Gender norms capture those behavioural norms that are applied differently depending on the agent's gender. For instance, while both men and women can be called "aggressive" or "assertive", when applied to women these terms are usually meant derisively. They are often complimentary for a man.

Much could be said of these normative categories. Most of all, I would like to remark on the sense of keeping Group 1 and Group 2 conceptually distinct. The normative subsets of Group 1 seem neutral in a fundamental way to the politics of identity and social customs of group identification. In other words, Group 1 categories require attending to the particularities of the agent and/or her practical context. The subsets of Group 2, however, fall squarely into that arena. The subsets of Group 2 produce pervasive forms of social stereotyping. The epistemic, moral, and political problem with stereotypes is that they are "extrapersonal"; they 
stand outside of and do not assess an individual's well-being, current state of mind, personality, capabilities, or interests. They should as a result be regarded as the least rationally satisfying of social coping infringements because they are substantially based on arational public custom. Unfortunately, assessing others using stereotypes remains satisfying to many people, possibly because of their arationality: stereotypes are descriptively superficial, resistant to reflective amendment, yet very powerful.

While Marxists aim to overthrow class stereotyping, disability activists engage developmental stereotypes, ethnographers and postcolonialists dismantle cultural stereotypes, it is left to feminists, gender and queer theorists to address and attempt to uproot gender stereotypes. Having introduced a way to classify core norms called on in assessing the (in)appropriateness of actions expressing emotion, I wish now to make a modest contribution to this third project.

\section{II}

To begin, it must be stated that gender stereotyping is, in our society at least, misogynistic. Women's opportunities for expression and action, not heterosexual men's, tend more often to be foreshortened because of gender stereotypes. It is true that men are called "wimps" or "saps" (usually by other men) more readily than women are when they express sadness or self-pity. Yet, women expressing strong, self-assertive emotion are standardly assessed by both men and other women as acting inappropriately. Women are socially expected to avoid behaviours such as acting assertively, demanding things loudly, showing fierce, self-interested emotion. Particularly compelling support for this is gleaned from Susan Brison's account of the empowering effect of women's self-defense courses on victims of sexual assault; women are often surprised at how difficult the simple act of yelling "No!" can prove to be (14).

As treated by classic and recent feminist texts, there is a story concerning "women's nature" that has held and still holds traction in Western patriarchal societies: the idea that women are perennially at risk of "losing their heads" and acting out their emotions, to their own shame. The misogynistic suppositions of that story go something like this: while man is the rational sex, his virtue and self-transcendence lying in logicdictated thought and action, "woman is Other", as de Beauvoir classically put it: sensuous, sensitive, and sentimental. Hers is the sex most "in tune" with the human senses and bodily nature, and, whether as a result of this or not, her sometimes only dimly conscious emotions, rather than her fully conscious appreciation of reasons, are her chief guides in thought and action. Self-transcendence is much harder for her to achieve because of this, and woman's truest virtue lies in a mild and gentle emotional life, and 
in a graceful, non-assertive bodily language (see Young). Vehement, even violently intrusive public displays of emotional upheaval and turmoil are as a consequence best interpreted as signs of her ill health, of her derangement or hysteria (Bordo 311, 316).

We are all familiar with this story, which is in reality the entrapment of women, an a priori curtailing of their possibilities for action and voice. Even today there are plenty of men and women who find recourse to its suppositions justified. A particularly illuminating case is worth looking at in more depth. This is the case, treated thoughtfully by Nancy Potter in a recent chapter contribution (Problem), of anger expression in women diagnosed with Borderline Personality Disorder (BPD).

As Larry May points out, violent, self-interested emotions such as anger are so commonly expressed in adolescent and adult males that "we all come to expect it" (8). It is not expected, however, that women, and especially young women, get angry and lash out in their anger. Nonetheless, it is taken for granted that anger can be an appropriate response, given certain conditions. Aristotle's analysis of rationally appropriate anger has yet to be surpassed: "Let anger be [defined as] desire, accompanied by [mental and physical] distress, for conspicuous retaliation because of a conspicuous slight that was directed, without justification, against oneself or those near to one" (Rhetoric 2.2.1 1378a 30-32; G. A. Kennedy translation). Certainly, a woman can experience these conditions and express herself through anger. If she is consequently labeled "crazy" or "hysterical", what has gone awry? Marilyn Frye argues that women's anger at perceived moral injustice against their person is peremptorily trivialized, rather than taken seriously; mocked, rather than treated with respect; pathologized, rather than taken as rational (89). "When it comes to women's claims of injustices and injuries," Potter writes, "women are told to stop 'playing the victim,' to stop blaming others for their plight, and to take responsibility for their lives" (61).

$75 \%$ of patients diagnosed with Borderline Personality Disorder are female (Potter 60). BPD, as described by the Mayo Clinic, is

... an emotional disorder that causes emotional instability, leading to stress and other problems. With [BPD] your image of yourself is distorted, making you feel worthless and fundamentally flawed. Your anger, impulsivity and frequent mood swings may push others away, even though you desire loving relationships.

Not surprisingly, as Marsha Linehan has shown, gender norms come into play in assessing individuals for BPD diagnosis: "behaviour that is labeled 'assertive' in men may be labeled 'aggressive' in women," she 
writes. "Perceived aggression begets retaliatory aggression, and thus the cycle of interpersonal conflict is born" (71). But the twist is still to come: many experts now see the "anger issues" of female BPD patients in terms of their inability to cope with strong emotions, rather than a desire and ability to express themselves through strong emotion. Female BPD patients tend to be "angerphobic," and their so-called telltale outbursts of anger are in fact akin to the allergic expulsion of a foreign body. "It is a recognized social phenomenon that girls and women are not taught that it is sometimes appropriate to be angry or what appropriate expressions of it look like," Potter explains. "Some are unable even to identify what anger feels like" (61). This new information changes the diagnostic picture radically. Therapists and clinicians tended to treat the expression of strong emotion in their female BPD patients as a matter of character, and in so doing, they became insensitive to the possibility that their patients could in fact be reacting rationally-acting reasonably angry-to real-time provocations (Potter 61-62). Potter offers striking anecdotal evidence to support this conclusion.

The case of misdiagnosis gets to the heart of the problem of interpersonal assessments of women's actions expressing emotions. Women's actions expressing especially aggressively self-assertive emotion are all too often judged inappropriate because they violate a viciously circular stereotype. In the moment of angry outburst, a female agent fails the first test of social (instrumental) appropriateness, due to her surpassing behavioural expectations. This failure in turn often shuts down further avenues of interpretation. Most significantly, whether a woman's emotional expression is evidentially rational becomes a secondary and non-obligatory question. In the case of at least some female BPD patients, this shutting down process has been internalized by the female agent herself, when she labels her own actions expressing emotion as inappropriate and irrational.

In the case of men, by contrast, since there is little behavioural restriction normatively imposed on their actions expressing aggressively self-assertive emotion (indeed, there is a pervasive norm that a man should stand up for himself, defend his honour, etc.), it is unlikely that they will fail the test of social appropriateness in their anger. And, further, men's actions are usually granted evidential warrantedness as if by default. Should a man perform an emotion in a way deemed socially inappropriate, it is likely that the observer will even then grant him charity and seek out his reasons for acting thusly. Hence, when men fail the social coping test, they are expected to give verbal evidence for their evidential rationality, and in this way justify the extreme action. A woman who fails the social coping test may not be offered this chance, the inappropriateness of her emotion instead being used as further proof of female irrationality. 
Potter thus rightly notes that women are in a double bind when it comes to actions expressing emotion, especially strong emotions such as anger. Where I differ with Potter and others is on the diagnosis of the precise source of this bind. In my view, it is not enough to say that women's anger, for instance, will not be perceived as reasonable because women are considered irrational. First of all, this is simply not true: women have never been considered inherently, permanently irrational. Rather, the historical masculinist picture has it that women are imperfectly rational beings. Men, too, are imperfectly rational beings, but rank higher on the scale.

As a diagnosis, secondly, this line of reasoning is too vague. My claim is that the adherence to social norms that limit women's emotional and behavioural repertoires is at the root of attributions of the irrationality of their actions expressing emotion. These social norms effectively cut off any significant consideration of a woman's evidential rationality and selfrelevant coping in a given context. Put in other words, no matter how a woman acts and on what epistemic and evaluative foundation she does so, assuming gendered coping norms are in place, her rational agency is likely to be undermined or at least doubted through the use of biased assessments that hinder and displace other means of normative assessment.

\section{III}

Having begun to identify the normative prioritization at play in the case of assessing women's actions expressing emotion, I can say that my account is in one sense an optimistic one, since it locates a core source of misogyny in behavioural norms and expectations, rather than ontological difference or gender essences. What remains to be stated are which norms one ought to prioritize in assessing another's actions expressing emotion. What norms ought serve as gate-keepers for sorting such actions into acceptable and unacceptable, healthy and unhealthy? That gender stereotypes ought be rejected is only the first (and to be expected) conclusion of this project. This final section will suggest other preliminary conclusions, framed within responses to two objections I can imagine being levelled against my optimistic argument.

Objection 1. What if the standards of rationality are gendered?

Genevieve Lloyd, in her classic analysis The Man of Reason, argues that "Our trust in Reason that knows no sex has ... been largely self-deceiving" (xix). If this is the case, then my sourcing of gender bias to social norms of instrumental rationality is specious - the bias being far more deep-rooted in the very nature of thinking. However, I am not eager to draw such a radical conclusion, even while I find Lloyd's description of the historical masculinization of rationality entirely plausible. 
To be brief, it does not follow from the historical laying claim to reason of one gender (and class and ethnicity) that the capacity itself is originally in service to the self-image of that purported owner. Reason as a "faculty" was certainly appropriated by male culture. And "emotionality" was imposed, and also frequently embraced, by women. Both of these attributions proved disempowering for women, as Sandra Bartky notes (102). Still, the capacity to reason itself - and to learn to reason wellamounts to nothing political or sinister on its own, in my view, but only the learning and rehearsing of a set of cognitive skills. As a result of male appropriation, reasoning may have taken on sinister metaphorical connotations. But no metaphor can displace its foundation, which in this case is an original, gender-neutral cognitive capacity. In the first chapter of Maternal Thinking, Sara Ruddick articulates her difficult relationship to Reason and her enduring commitment to reasoning, and in so doing offers us a way out of the dilemma:

Yet however rebellious I felt, I did not doubt, and I do not now, that as destructive as Western ideals of Reason may be, the capacity to reason is a human good. I know what a pleasure it is to learn, experiment, imagine, discover, design, and invent. There is real strength in steady judgment, self-reflectiveness, clear speech, and attentive listening. ... I have never been persuaded that there is anything precious, or specifically bourgeois, or merely Western, or exclusively masculine about the human needs and pleasures of reason. (8-9)

Ruddick's question is not: how can we rid ourselves of Reason, but how can we "honour Reason" differently, which is the question I also wish to ask.

Objection 2. Is gender entirely irrelevant to assessing another's action expressing emotion?

My initial impulse is to respond vaguely: Gender is not any more or less important than any other features which form a person's particular identity. However, this non-committal response short-changes a deeper conviction, which is that gender, class, ethnicity, sexuality, profession, and cognitive development are not genuinely salient to the scenario under examination in this paper, namely that of giving space for and recognizing the intelligence in (if perhaps also the problematic or even faulty reasoning underlying) another's emotional life. Grasping the worth behind another's emotions may indeed require awareness of the agent's own sense of belonging to some or all of these socio-political classifications. What is ultimately at stake, as Potter rightly notes, is the expressive individual's real-time sense of herself as a competent (rational) agent (63). In so doing, the observer's own sense of the agent's "really" belonging to these classifications (and respective stereotypes) should be left out of the 
equation, as difficult as it may be to do. Stereotyping on the part of the observer blocks perceiving the agent in her intelligent reaching out through emotional expression.

Having exposed gender prejudice within typical assessments of others' actions expressing emotion, it is true that we are left with fewer "quick and dirty" means by which to judge their appropriateness. How shall we fill that gap? The answer that suggests itself requires replacing stereotypes with relational norms. A sense of one's investment in and relation to the expressions of another is basic to the faithful and charitable appraisal of their actions expressing emotion. Further, since empathic listening helps legitimate an agent's emotional expressions and narrative imagining helps make them intelligible, empathy and narrative imagination are both excellent candidates for developing a keener sense of relationality. Their training should be encouraged at all levels of education and socialization.

It is true that our emotional lives are fundamentally concerned with what we ourselves care about within our own sphere of action and influence, what we are concerned to preserve and nurture, what we eschew and eliminate or ignore. When our concerns, values and access to information align with those of another, his or her actions expressing emotion will speak to us far more readily than in cases when our concerns and our access don't overlap. It is in these latter cases, though, when we are met with our own incomprehension of another's emotional expression, that we ought to be most prepared to engage our capacity for empathy and imagination.

\section{Works Cited}

BARTKY, Sandra. "Feeding Egos and Tending Wounds: Deference and Disaffection in Women's Emotional Labor." Power, Dignity, and Social Structure: Readings in Multicultural Social Theory. Ed. Rogers. New York: McGraw Hill, 1995.

Bordo, Susan. "The Body and the Reproduction of Femininity: A Feminist Appropriation of Foucault." Gender/Body/Knowledge: Feminist Reconstructions of Being and Knowing. Eds. A. M. Jaggar and S. R. Bordo. New Brunswick: Rutgers University Press, 1989. 13-33.

BRISON, Susan. Aftermath: Violence and the Remaking of the Self. Princeton: Princeton University Press. 2002. 
FRYe, Marilyn. Politics of Reality: Essays in Feminist Theory. Berkeley: Crossing Press, 1983.

GreEnspan, P. "Emotions, Rationality, and Mind/Body." Philosophy and the Emotions. Ed. A. Hatzimoysis. Cambridge: Cambridge University Press, 2003. 113-126.

Linehan, M. Cognitive-Behavioural Treatment of Borderline Personality Disorder. New York: Guilford Press, 1993.

LlOYD, G. The Man of Reason: "Male" and "Female" in Western Philosophy, $2^{\text {nd }}$ ed. Minneapolis: University of Minnesota Press, 1993.

MAY, L. Masculinity and Morality. Ithaca: Cornell University Press, 1998. "Mayo Clinic Borderline personality disorder defined." Mayo Clinic. Web. 16 Dec 2011.

Potter, N. N. "The Problem with too much Anger: A Philosophical Approach to Understanding Anger in Borderline Personality Disordered Patients." Fact and Value in Emotion. Eds. L. C. Charland and P. Zachar. Philadelphia: John Benjamins, 2008. 53-64.

RudDICK, S. Maternal Thinking. Boston: Beacon Press, 1995.

SANDEL, M. "The Case Against Perfection: What's Wrong with Designer Children, Bionic Athletes, and Genetic Engineering." Atlantic Monthly 293, no. 3 (2004): 50-54, 56-60, 62.

YounG, I. M. "Throwing Like a Girl: A Phenomenology of Feminine Body Comportment, Motility and Spatiality." Human Studies 3 (1980): 137-156. 